Vietnam Journal of Mechanics, VAST, Vol. 27, No. 2 (2005), pp. 86-95

\title{
PLASTIC DAMAGE EVOLUTION IN MULTILAYER COATINGS/DUCTILE SUBSTRATE SYSTEM UNDER SPHERICAL INDENTATION: INFLUENCE OF A METALLIC INTERLAYER
}

\author{
Le Minh Quy, Tran ICh Thinh \\ Hanoi University of Technology
}

\begin{abstract}
Spherical indentation problems of ceramic coatings/metallic inter-layer/ductile substrate were investigated numerically by axisymmetric finite element analysis (FEA) for two typical ceramic coatings with relatively high and low elastic modulus deposited on aluminum alloy and carbon steel. Various indenter radius-coating thickness ratios and interlayer thickness-coating thickness ratios were used in the modeling. Plastic damage zone evolution were discussed in connection with model parameters. The results showed that the suitable metallic interlayer could improve resistance of ceramic coating systems through reducing the plastic damage zone size in the substrate under spherical indentation.

Key words: Finite element, ceramic coatings, indentation, interlayer;
\end{abstract}

\section{INTRODUCTION}

Laminated structures composed of hard brittle ceramic outer layers and soft ductile substrates are commonly used in a variety of industrial fields for anti-wear application, corrosion protection, thermal insulation, and electrical isolation, etc [1,2]. Under contact conditions, the hard coatings ensure in general very high stresses. These situations lead to the damage or the failure of the coating/substrate systems. There are several different damage modes experimentally observed: plastic deformation in the substrate, surface ring crack, interface crack and delamination as schematically illustrated in Fig. 1a. The indentation problems of a sphere into elastic layers bonded to an elastic half-space have been investigated by integral transform method (see, e.g., [3-5]) and finite element methods (see, e.g., $[6,7]$ ).

Concerning elastic layers on elastic-plastic substrates, by means of finite element calculations, stress and deformation fields of coatings, plastic deformation in the substrates and other related information were investigated for very few typical combinations of ceramics coatings and metallic substrates under spherical indentation.

E. Weppelmann and M.V. Swain [8] presented a stress analysis within TiN thin film on stainless steel loaded a spherical indenter with various ratios of coating thickness to indenter radius. M.R. Begley et al. [9] investigated the influence of substrate yield strength, substrate strain hardening and friction coefficient on the surface plastic strains for a fixed ratio of coating thickness to indenter radius. Fischer-Cripps et al. [10] analyzed the extension of the plastic zone in the substrate of plasma-sprayed alumina:titania coated on a soft steel under spherical indenter.

Thomsen et al. [11] and J. Michler [12] studied the maximum surface stresses in diamond-like-carbon (DLC) coatings and coating fracture possibility of DLC coatings on steel in correspondence to indentation experiments with spherical indenters. More recently, K. Sriram et al. [13] carried out extensive finite element calculations for TiN coatings on elastic-perfectly-plastic steel substrate. They studied the influence of yield stress of the 
substrate on stress distribution in the film and on the development of cylindrical cracks in the coating surface.

Introduction of inter-layers is widely applied in such ceramic coating structures to improving the bond strength of the coating systems, and reducing the thermal and mechanical properties mismatch between ceramic outer layers and ductile substrates. Metallic inter-layers can be a pure metal or an alloy [1-2]. The present work is aimed at evaluating the effects of ductile metallic inter-layers on plastic deformation damage growth in the substrate coatings during spherical indentation. The problems such of stress distribution in this coating system under spherical indentation may be presented in orther papers due to the length. Spherical indentation problems of ceramic coatings/metallic inter-layer/ductile substrate are investigated numerically by an axisymmetric FEA for two typical ceramic coatings with relatively high and low elastic modulus deposited on aluminum alloy and carbon steel, which have been known as common ductile substrates used in engineering. Various indenter radius-coating thickness ratios and interlayer thickness-coating thickness ratios were used in the modeling. Plastic damage zone evolution are discussed in connection with model parameters.

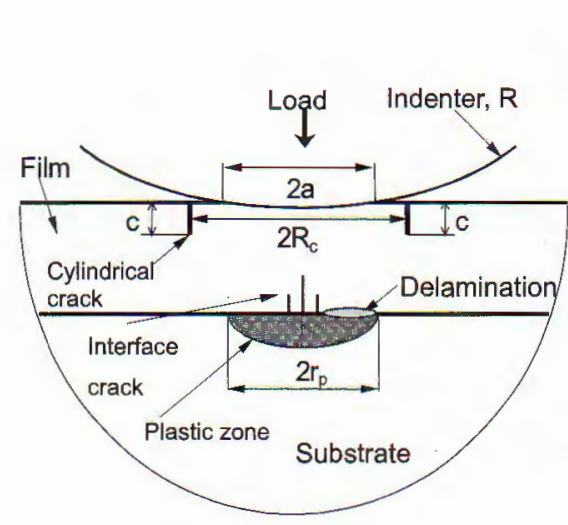

a)

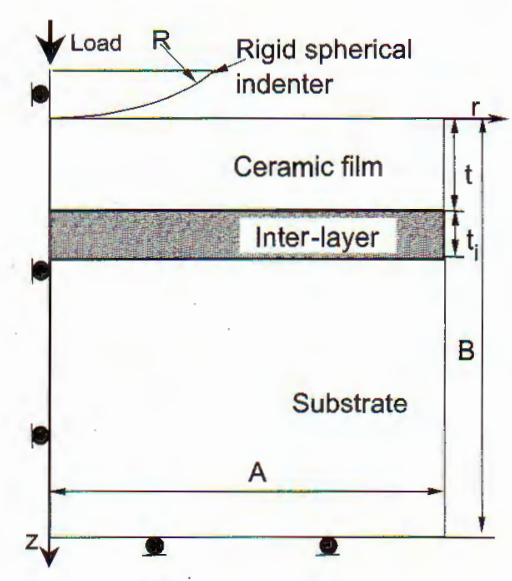

b)

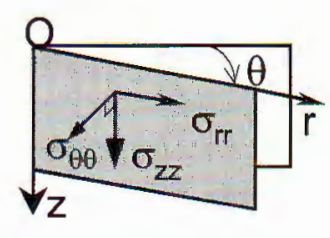

c)

Fig. 1. Schematic representation of spherical indentation into bonded half-space:

a) contact zone with typical failure modes;

b) two-dimensional presentation of indenter and specimen;

c) three-dimensional presentation with coordinate system and normal stress notations.

\section{THE COMPUTATIONAL MODEL}

\subsection{Description of studied materials}

Under spherical indentation, hard brittle ceramic coatings are assumed to behavior elastically. Metallic inter-layers and substrates can undergo plastic deformation with increasing indentation load according to Von Mises criterion [14]. The elastic-plastic behav- 
ior of metallic materials are modeled by power law description as follows:

$$
\begin{aligned}
& \sigma=E \varepsilon, \quad(\sigma \leq Y), \\
& \sigma=E \varepsilon^{n}, \quad(\sigma \geq Y),
\end{aligned}
$$

$K$ is a strength coefficient, $n$ is the strain-hardening exponent, $Y$ is the initial yield stress. They have the following relation:

$$
Y=E \varepsilon_{y}=K \varepsilon_{y}^{n}
$$

where $\varepsilon_{y}$ is the corresponding yield strain. The total strain $\varepsilon$ is a sum of elastic strain $\varepsilon_{e}$ and plastic strain $\varepsilon_{p}$ :

$$
\varepsilon=\varepsilon_{e}+\varepsilon_{p}
$$

The aluminum alloy and carbon steel are elastic-perfectly-plastic. Their chosen values of elastic modulus and yield stress for modeling reported in Table 1 represent typical aluminum alloy and carbon steel used in engineering $[15,16]$. Two values of elastic modulus of ceramic coatings, which are relatively high and low are used in modeling.

Metallic inter-layers can be a pure metal (e.g. Ni, Cr, Ti, etc) or an alloy type such as TiAl, NiAl, NiCr, NiCrAl, NiCrAlY, NiCoCrAlY, etc [1-2]. Their mechanical properties such as hardness, elastic modulus, yield stress and strain-hardening exponent vary in large intervals, depending on their content of metallic elements, microstructure (e.g. grain size) and deposition methods (see, e.g. [2]). The metallic inter-layers are ductile rather than hard. They are softer than ceramic top coatings but they can be harder than metallic substrates. Their Vickers hardness is $H V 3=179 \pm 19$ for the case of air plasma-sprayed $\mathrm{NiAl}$ up to $H V 3=543 \pm 23$ for vacuum plasma-sprayed NiCoCrAlY [2]. The elastic modulus of NiAl was estimated by four-point bending tests as $78 \mathrm{GPa}$ and $166 \mathrm{GPa}$ for air plasma-sprayed and high velocity oxy-fuel method, respectively [17]. The elastic modulus of vacuum plasma-sprayed $\mathrm{NiCrAlY}$ and $\mathrm{NiCoCrAlTaY}$ were evalua,ted about $200 \mathrm{GPa}$ and $163 \mathrm{GPa}$ by tensile test [2]. The yield stress was estimated as $1.2 \mathrm{GPa}$ for vacuum plasmasprayed NiCoCrAlTaY by tensile test [2]. By spherical indentation tests, the yield stress was evaluated as $0.73 \mathrm{GPa}$ for plasma-sprayed $\mathrm{NiCrAlY}$ interlayer [18], and $0.46 \mathrm{GPa}$ for $\mathrm{NiAl}$ deposited by high velocity oxy-fuel method [17]. Metallic inter-layers usually present a significant strain hardening $[17,18]$.

Therefore, for interlayer, the elastic modulus, yield stress and strain-hardening exponent are taken as $110 \mathrm{GPa}, 0.68 \mathrm{GPa}$, and 0.25 , respectively. The Poisson's ratio are chosen $0.3,0.25$, and 0.2 for metallic materials, ceramic coating of low elastic modulus and ceramic coating of high elastic modulus, respectively. Table 1 resumes the mechanical properties of materials used in modeling. 
Table 1 Mechanical properties of modeled materials

\begin{tabular}{lllll}
\hline Materials & $\begin{array}{l}\text { Elastic } \\
\text { modulus } \\
(\mathrm{GPa})\end{array}$ & $\begin{array}{l}\text { Poisson's } \\
\text { Ratio }\end{array}$ & $\begin{array}{l}\text { Yield } \\
\text { strength } \\
(\mathrm{GPa})\end{array}$ & $\begin{array}{l}\text { Strain } \\
\text { hardening } \\
\text { exponent }\end{array}$ \\
\hline $\begin{array}{l}\text { Steel Substrate } \\
\begin{array}{l}\text { Aluminum alloy } \\
\text { strate }\end{array}\end{array}$ & 207 & 0.3 & 0.38 & 0 \\
$\begin{array}{l}\text { Interlayer } \\
\text { Ceramic I: Alumina- }\end{array}$ & 70 & 0.3 & 0.140 & 0 \\
$\begin{array}{l}\text { 30\% Zirconia } \\
\text { Ceramic II: TiN }\end{array}$ & 110 & 0.3 & 0.680 & 0.25 \\
\hline
\end{tabular}

\subsection{Modeling aspects and finite element model}

Due to the symmetry, only one-half of the system is used in modeling as shown in Fig. 1b with respect to the $r-z$ coordinates system. Here, the origin of the coordinates corresponds to the point of intersection between the centerline of the structure and the surface of coating in the initial (un-deformed) configuration. The $z$-axis coincides to the centerline of the structure and expends downward. The $r$-axis, radial axis, belongs to the surface of coating and expends outward. Associated to this coordinate system, there are six stress components. Three normal stress components: $\sigma_{r r}$ (radial stress), $\sigma_{z z}$ (axial stress), $\sigma_{\theta \theta}$ (circumferential stress being perpendicular to $r-z$ plan) are described in Fig. 1c.

The spherical indentation of the coating/substrate was carried out numerically by MARC/MSC finite element code [19]. The indenter was modeled as a rigid sphere of radius $R$ The specimen was modeled as a large cylinder of height $A$ and radius $B(A=B>50 a$, in all cases, where $a$ is contact radius, see Fig. 1). These dimensions were found to be large enough to approximate a semi-infinite half-space for indentations. This was evidenced by an insensitivity of calculated results to further increase in specimen size.

Frictionless roller boundary conditions were applied along the centerline and bottom. Outside surfaces were taken as free surfaces. The interaction between the rigid indenter and specimen was modeled by contact elements with no friction. The residual stresses were not taken account in the analysis. Large strain four-node elements were used.

To account properly for the high stress gradients under the indenter, estimate accurately of the peak tensile stress on the surface of ceramic coatings, and for an accurate detection the contact nodes, the mesh was made very fine locally near the contact area with an element size of $t / 64$. The mesh was then gradually coarser outwards. The contact was occurred at least with 45 elements at the first increment, and with approximately 200 elements at the maximum indentation load (final increment).

Both the force-controlled and displacement-controlled procedures were used in this work. The automatic depth increment scheme was used to determine the appropriate size of the load increments. Several values of indenter radius-coating thickness ratio $(R / t)$ were used in the present study. The mesh was adapted separately for each geometry. Therefore, several meshes were used. The typical mesh consisted approximately of 9000 four-node elements. 
It should be emphasized that since a continuum analysis with homogeneous material properties is performed here, the results obtained would depend only on the ratios of different length dimensions and not on their absolute values. Thus, for example, from analytical solutions for contact between a sphere and an elastic half-space (see, e.g., K.L. Johnson [20]), as well as from dimensional considerations, it may be expected that the load $P$ during indentation of a ceramic film bonded to a soft substrate (as in Fig. 1) would have the following functional form:

$$
P=E_{f} R^{2} f\left(\frac{h}{t}, \frac{t}{R}, \frac{E_{s}}{E_{f}}, \frac{Y_{s}}{E_{s}} \text {, other materials parameters }\right),
$$

where $E_{s}, E_{f}$ are respectively the elastic modulus of the the substrate and ceramic film. $Y_{S}$ is yield stress of the substrate, $h$ is indentation depth, other notations are shown in Fig. $1 . h / t$ is the ratio of the indentation depth to coating thickness and is a measure of the compressive axial strain in the film at the indenter axis. Therefore, the normalized indentation load, $P^{*}=P /\left(E_{f} R^{2}\right)$, is used, and all lengths are scaled by coating thickness, $t$, otherwise it will be noted.

\subsection{Validation of the finite element model}

\subsubsection{Hertzian contact}

The finite element model is compared firstly with the analytical results of Hertzian contact [20] for elastic half-space under spherical indentation. The calculations for validation were carried out for elastic half-space with elastic modulus $E=200 \mathrm{GPa}$, Poisson's ratio $?=0.25$. It is the case of sintered Zirconia bulk ceramic [21]. The rigid indenter has radius of $6 \mathrm{~mm}$. Fig. 2 shows stress distributions along the surface ( $r$-axis) and along centerline (z-axis) for the indentation load of 100N. Fig. 3 shows the load-indentation depth curve.

The data points correspond to Hertz solution and the solid lines are obtained by finite element analysis. It was found that a good agreement between Hertz solution and FEA was achieved.

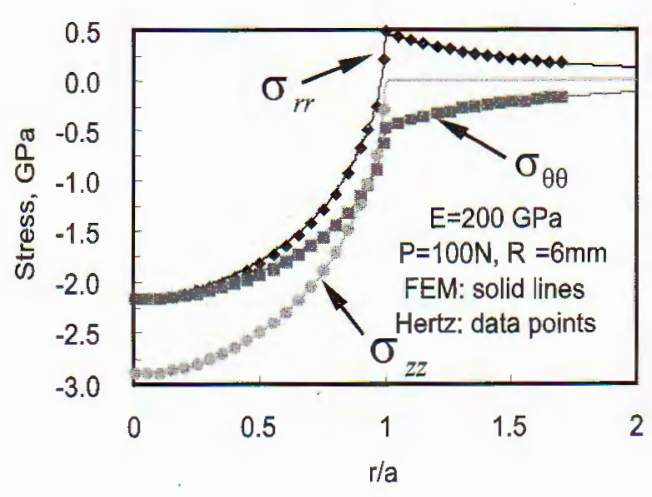

a)

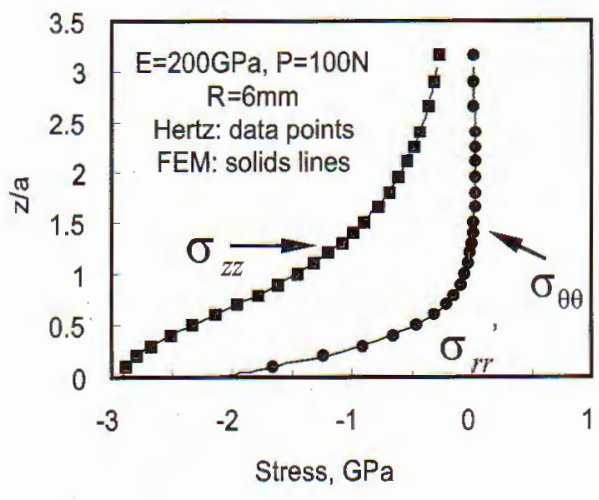

b)

Fig. 2. Validation of FEA: stress distributions obtained by FEA and Hertz's solution for elastic contact of homogeneous solid.

a) along the surface $(z=0)$, b) along the centerline $(r=0)$ 


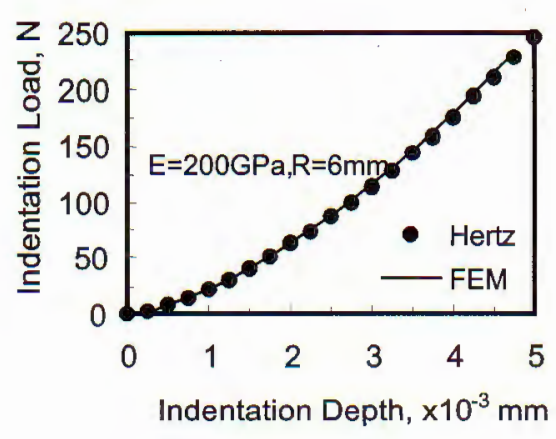

Fig. 3. Validation of FEA: indentation load depth curve obtained by FEA and Hertz's solution for elastic contact of homogeneous solid.

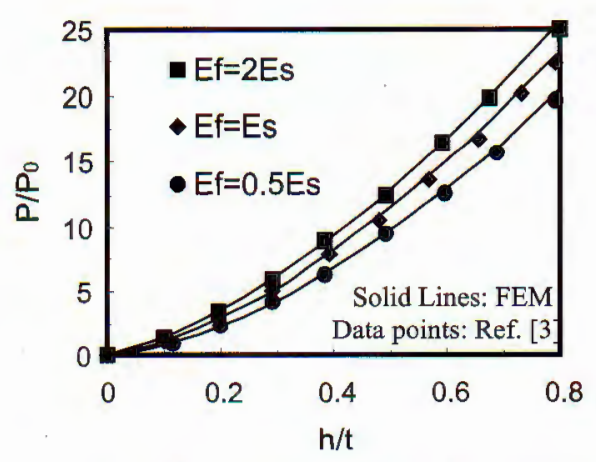

Fig. 4. Validation of FEA: indentation load-depth curves obtained by FEA and [3] for elastic contact of coated body.

\subsubsection{Spherical indentation into elastic coated body}

Second validation has been conducted by comparing the finite element model with the results obtained by O'Sullivan and King [3]. These authors used Papkovich-Neuber potentials and Fast Fourier Transform to solve the problem of spherical indentation into elastic coated body. For this purpose, finite element analysis was investigated for rigid spherical indentation into an elastic mono-layer coated on an elastic substrate. The condition of indentation and the materials parameters used in finite element calculations were taken the same as those used in [3].

Therefore, the indenter radius, $R$, was equal to ten times of coating thickness, $t: R=$ 10t. The elastic modulus of the substrate $E_{s}$, was kept fixed. Three cases were studied: $E_{s}=0.5 E_{f}$, Ef and 2Ef. Ef is elastic modulus of the coating. The Poisson's ratio of the coating and the substrate were taken as 0.3 .

Fig. 4 shows the indentation load-depth curves obtained by finite element analysis and [3]. The indentation depth, $h$, was normalized by coating thickness, $t$. The indentation load, $P$, was normalized by $P_{0} . P_{0}$ is the indentation load with contact radius $a=t$ in the case of Hertzian contact between the indenter and the substrate (in the absence of the outer layer). A good agreement between the results of [3] and those obtained by finite element calculations was found.

\section{RESULTS AND DISCUSSION}

The equivalent plastic strain is determined by the following formula $[19,22]$ :

$$
\varepsilon^{-p} \int \dot{\vec{\varepsilon}}^{p} d t=\int\left(\frac{2}{3} \dot{\varepsilon}_{i j}^{p} \dot{\varepsilon}_{i j}^{p}\right)^{\frac{1}{2}} d t .
$$

The plastic zone size is defined in the Fig. 1a as the maximum extend of the substrate plastic zone from the point of the intersection of the axis $z$ and the interface $r_{p}$.

It was found that, for coating/interlayer/substrate system, during indentation, the plastic damage can firstly occur in the substrate, and then, in the interlayer when the indentation load reaches a certain value or inversely, it initiates firstly in the interlayer. It 
depends upon the values of indenter radius-thickness ratio, $R / t$, and interlayer thicknesscoating thickness ratio, $t^{*}=t_{i} / t$. The plastic zone size in the interlayer is always smaller than that in the substrate. This study considered only plastic damage accumulation in the substrate.

The evolution of normalized plastic zone size $r_{p} / t$ versus normalized indentation load $P^{*}$ is shown in Fig. 5 for two ceramic coatings deposited on the steel substrate with different values of indenter radius-coating thickness ratio. In the cases of low indentation load (corresponding to indentation depth-coating ratio, $h / t<0.03$, for our cases), in which the wear tests are generally carried out, the interlayer decreased the plastic damage accumulation in the substrate. When $R / t$ is equal to 60 , the influence of the interlayer into plastic zone is slight. This influence is increased for thicker coatings $(R / t=30$ and $120 / 7)$. For thickest coatings, $R / t=120 / 7$, even a thin interlayer $\left(t_{i}=t / 7\right)$ can protect effectively the substrate from plastic damage. While increasing interlayer thickness, the plastic damage zones size is decreased.

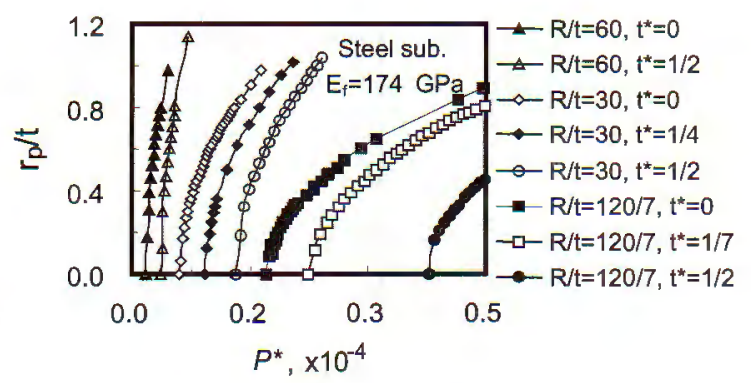

a)

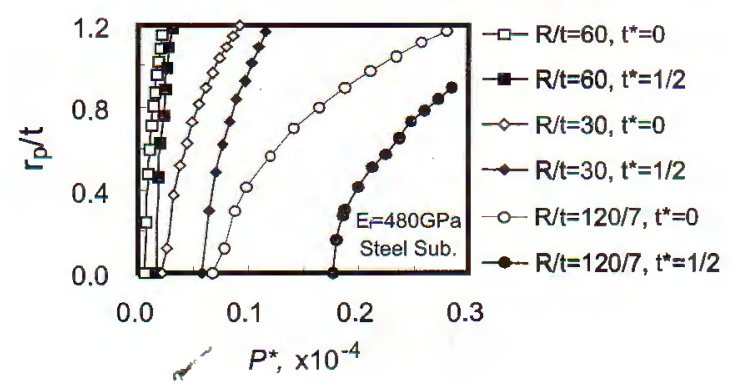

b)

Fig. 5. Normalized substrate plastic zone size versus $P^{*}$ for ceramic coated on steel:

a) $E_{f}=174 \mathrm{GPa}$ and b) $E_{f}=480 \mathrm{Gpa}$.

The plastic damage in thinnest coatings $(R / t=60)$ is very sensitive to the indentation load. A small increase in indentation load can cause a large increase in plastic deformation in the substrate. However, this situation is less sensitive for thicker coatings $(R / t=120 / 7)$.

To compare the influence of elastic modulus mismatch between ceramic coating and substrate into the plastic damage in the substrate, it is better to consider the indentation under controlled displacement. The numerical results also indicated that, a large elastic modulus mismatch between the ceramic coatings and the substrate causes severe plastic 
damage in the substrate as shown in Fig. 6 for the case $R / t=60$.

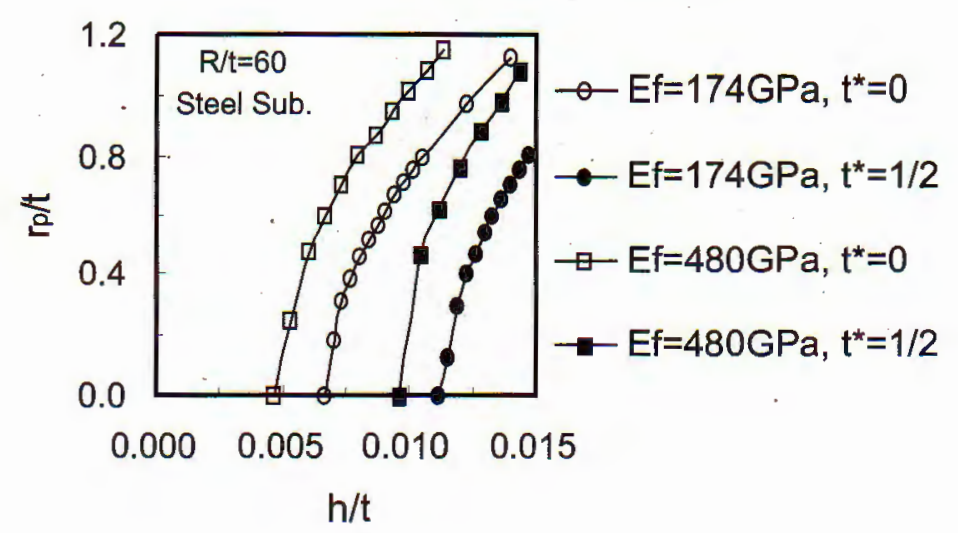

Fig. 6. Normalized substrate plastic zone size versus indentation load for thinnest coatings, $R / t=60$.

\section{CONCLUSIONS}

Using the suitable metallic inter-layer, the ceramic coating/metallic inter-layer/substrate systems have the following advantages compared to ceramic coating systems without interlayer:

1. Plastic damage in substrates occurs when indentation loads reach certain values. For thin coatings, interlayer has a slight effect for protecting substrate from this type of failure. For thick coatings, inter-layer reduces effectively plastic damage.

2. Even a thin interlayer can delay the failure under this form.

3. Large elastic modulus between ceramic layers and substrate cause severe plastic damage in the substrate.

Acknowledge. This publication is completed with financial support from the Council for National Science of Vietnam.

\section{REFERENCES}

1. K. Holmberg and A. Matthews. In: D. Dowson, Editor; Coatings Tribology, Elsevier, 1994.

2. Lech Pawlowski, The Science and Engineering of Thermal Spray Coatings, Chichester, New York: Wiley, 1995.

3. T. C. O'Sullivan and R. B. King, Sliding contact stress field due to a spherical indenter on a layered elastic half-space, Jöurnal of Tribology 110 (1988) 235-240,

4. C. H. Kuo and L. M. Keer, Contact stress analysis of a layered transversely isotropic halfspace, Journal of Tribology 114 (1992) 253-262.

5. S. Plumet and M. C. Dubourg, A 3-D model for a multilayered body loaded normally and tangentially against a rigid body: application to specific coatings. ASME Journal of Tribology. 120 (1998) 668-676.

6. S. Van der Zwaag and J. E. Field, The effect of thin hard coatings on the Hertzian stress Field, Philosophical Magazine A 46, 1982, pp. 133-150. 
7. H. Djabella and R. D. Arnell, Finite element analysis of the contract stresses in an elastic coating on an elastic substrate, Thin Solid Films 213 (1992) 205.

8. E. Weppelmann and M. V. Swain, Investigation of the stresses and stress intensity factors responsible for fracture of thin protective films during ultra-micro indentation tests with spherical indenters, Thin Solid Films 286 (1996) 111.

9. M.R. Begley, A.G. Evans and J.W. Hutchinson, Spherical impression of thin elastic films on elastic-plastic substrates, International Journal of Solids and Structures 36 (1999) 2773.

10. A. C. Fischer-Cripps, B. R. Lawn, A. Pajares and L. Wei, Stress analysis of elastic-plastic contact damage in ceramic coatings on metal substrates, Journal of the American Ceramic Society 79 (1996) 2619.

11. N.B. Thomsen, A.C. Fischer-Cripps and M.V. Swain, Crack formation mechanisms during micro and macro indentation of diamond-like carbon coatings on elastic-plastic substrates, Thin Solid Films 332 (1998) 180-184.

12. J. Michler and E. Blank, Analysis of coating fracture and substrate plasticity induced by spherical indenters: diamond and diamond-like carbon layers on steel substrates, Thin Solid Films 381 (2001) 119-134.

13. K. Sriram, R. Narasimhan, and S. K. Biswas, A numerical fracture analysis of indentation into thin hard films on soft substrates, Engineering Fracture Mechanics 70 (2003) 1323-1338.

14. R. Hill, The Mathematical Theory of Plasticity, Clarendon Press, Oxford, 1950.

15. ASM handbook, Vol. 1: Metals Handbook, Properties and Selection-Irons, Steels, and HighPerformance Alloys, 10th ed., Materials Park, OH: ASM International Handbook Committee, 1990.

16. ASM handbook, Vol. 2: Metals Handbook, Properties and Selection-Nonferrous Alloys and Special-Purpose Materials, 10th ed., Materials Park, OH: ASM International Handbook Committee, 1990.

17. S. Sampath, X. Y. Jiang, J. Matejicek, L. Prchlik, A. Kulkarni and A. Vaidya, Role of thermal spray processing method on the microstructure, residual stress and properties of coatings: an integrated study for NiAl bond coats, Materials Science and Engineering A $\mathbf{3 6 4}$ (2004) $216-231$.

18. S. Wuttiphan, A. Pajares, B. R. Lawn and C. C. Berndt, Effect of substrate and bond coat on contact damage in zirconia-based plasma-sprayed coatings, Thin Solid Films 293 (1997) 251-260.

19. MARC. MSC, Volume A: Theory and User Information, MSC Software Corporation, 2000.

20. K. L. Johnson, Contact Mechanics, Cambridge University Press, 1985.

21. J. F. Shackelford and W. Alexander, Materials Science and Engineering Handbook, CRC Press, third edition, 2001.

22. T. Belytshko, W. K. Liu and B. Moran, Nonlinear Finite Elements for Continua and Structures, Wiley, New York, 2000. 


\section{ÀNH HƯỞNG CỦA LỚP TRUNG GIAN BẰNG HỢP KIM ĐẾN BIẾN DẠNG DÉO TRONG KẾT CẤU CHỨA CÁC LỚP MẠ GỐM CHỊU TẢI TRỌNG TIẾP XÚC}

Vật liệu nhiều lớp khảo sát trong bài báo gồm một lớp mạ gốm, một lớp trung gian bằng hợp kim được phủ trên nền hợp kim nhôm hoặc thép các bon. Bài toán tiếp xúc của kết cấu nói trên với mặt cầu rắn tuyệt đối được khảo sát bằng phương pháp phần từ hữu hạn. Hai loại gốm điển hình có giá trị mô đun đàn hồi cao và thấp được ứng dụng trong mô hình tính toán. Tỷ số giữa bán kính quả cầu tiếp xúc và chiều dày lớp mạ gốm được phù, cũng như tý số giữa chiều dày lớp gốm và lớp trung gian bằng hợp kim được sừ dụng như tham số cưa mô hình tính toán. Biến thiên của vùng biến dạng dèo trên nền nhôm hoặc thép các bon được nghiên cứu trên cơ sớ các tham số cưa mô hình. Kết quá tính toán chì ra rằng nếu lớp trung gian được chọn hợp lý, thì độ bền của kết cấu nhiều lớp nói trên sẽ tăng đáng kể thông qua việc giảm kích thước vùng biến dạng dèo trên nền thép hoặc hợp kim nhôm trong quá trình tiếp xúc. 